\title{
An Experiment in Learning Intervention for At-Risk Students in Engineering Economy
}

\author{
William G. Sullivan, David G. Martin \\ Virginia Tech
}

\begin{abstract}
At Virginia Tech, over 1,000 students per year take a required course in engineering economy (ISE 2014). It is taught primarily to sophomores, and every year we see $20-25 \%$ of the class make Ds and Fs. Many of these ìat riskî students transfer out of engineering because of low grades in ISE 2014 and other core engineering courses. An experiment was conducted during the fall semester of 1997 to actively intervene in the education of ISE 2014 students who are at risk by offering help at a personal level. Clearly, the challenge is how to accomplish this with very limited resources in classes that average 175-200 students each.
\end{abstract}

\section{Introduction}

This paper describes the results of an experiment to encourage active learning participation by ìat riskî students in two large sections of engineering economy (approximately 200 students each) taught at Virginia Tech in the fall of 1997 using the DeGarmo, et al textbook [1]. At-risk students are students whose predicted final grade in the course is a ìîi or an îF.î Grade predictions were made during the summer of 1997 by using a multiple linear regression equation developed for 1,400 students during 1993-96 and reported by Sullivan and Daghestani [2].

In general, a sophomore student will make a ìnî in the course when his/her Virginia Tech QCA is in the bottom quartile of the College of Engineering (less than 2.0). Similarly, a ìî is predicted when a studentís Math SAT score falls in the bottom quartile of engineering students (less than 500). If a student is in the bottom quartile of QCA and Math SAT scores in the college, the student is predicted to fail the course. Additionally, advanced placement freshmen are at risk because their final grades are (on the average) on letter lower than the ìaverageî sophomore who makes a ìcî in engineering economy.

\section{The Experiment}

During the fall of 1997, at-risk students identified during the preceding summer were organized into two optional recitation groups (one for the 10 am class and one for the $2 \mathrm{pm}$ class). These groups were taught by a veteran graduate teaching assistant (GTA). Non at-risk students were assigned to other optional recitation groups (two each at 10 am and $2 \mathrm{pm}$ ). Thus, one-third of the recitation groups were comprised of students who were predicted to perform poorly (a grade of D or $\mathrm{F}$ ) in the 10 am and 2 pm sections of the class. 
Several types of positive learning intervention were directed at high-risk students in the two experimental recitation groups. One intervention method was simply to offer a ìhelp-sessionî recitation group that contained only 60 students (out of a Monday-Wednesday lecture group of 180-200 students!). Because attendance was voluntary, an average of 25-40 students actually attended the Friday recitations. These small groups are designed to encourage good rapport between the GTA and the students. (Many universities already enjoy this luxury, but the trend nationwide appears to be towards larger engineering economy classes.)

Other intervention tactics included challenges to the experimental groups such as ìa free pizza to the student in each group whose test 2 score is most improved,î current events related to engineering economy sent via e-mail, and active participation of the professor in the recitation groups. (Normally the professor gives the Monday-Wednesday lectures but does not attend the Friday recitations.) These types of intervention were intended to ìpersonalizeî the large class and form a direct communication link with $\underline{\text { each }}$ at-risk student.

Perhaps the most important intervention strategy was the use of constant e-mail contact between the GTA and the students concerning up-coming homework assignments and exams. Each student was encouraged to contact the GTA at any time via e-mail with their questions or concerns. Using a mailing list, the GTA would copy the entire question (omitting the senders name) and send the question with a reply to both experimental groups. This allowed the members of each group to receive additional information on nearly all topics, even if they did not attend the weekly recitation sessions.

\section{Results of the Experiment}

In the experimental groups, test 1 and 2 and final exam scores for all at-risk students were, as expected, lower than the overall class average. But the hypothesis was that they would perform better than at-risk students in other sections of engineering economy taught by different instructors. In the non-experimental sections, at-risk students were randomly assigned to recitation groups and were not exposed to the intervention tactics utilized in the two experimental groups (10 am and $2 \mathrm{pm}$ ). Based on grades assigned from final weighted scores (not including bonus points) in engineering economy, the results in Table 1 suggest that intervention resulted in final grades tending to be higher for 10 am and 2 pm at-risk students compared against at-risk students in the 9 am and $1 \mathrm{pm}$ sections. This result can be seen in the computed grade point average (GPA) and in the net change in actual versus predicted grades. For example, if the predicted grade is a ìDî and a student receives a ìC,î the net change is +1 . A predicted grade of iFî̀ but an actual grade of îî is a net change of +2, and so on. If predictions of Ds and Fs (based on the multi-linear regression model) are reasonably accurate, one would expect to observe a net change of 0 for a given section. Obviously, students whose predicted grades were a $\mathrm{C}$ or higher were omitted from Table 1.

Another interesting finding was that the students who were predicted to do well in the 10 am and 2 pm classes (i.e. receive a final grade of A or B) but did not receive intervention techniques, did not perform as well as originally anticipated as a group. In the 10 am class the predicted average 
of at-risk students was 1.581, while their actual average at the end of the course was 2.186. Intervention resulted in a positive difference of 0.605 . However, the non-intervention group was anticipated to have a final average of 3.429, but only achieved an average of 3.086. Similar results occurred in the 2 pm class are shown in Table 2.

\section{Lessons Learned}

That intervention results in better grades is not a surprise. From Table 1 it is apparent that the net change in grades for the experimental groups is four times greater (net change of +8 versus +2 ) than for the non-experimental groups. This is not statistically significant, but it is merely an indication of the positive impact of intervention tactics in large sections of engineering economy at Virginia Tech.

It is somewhat surprising that the at-risk students who received intervention did so much better than expected when compared to the students who were supposed to do well but received no intervention. This data, from Table 2 , shows that perhaps all students could benefit from intervention techniques in some form or other.

Table 1. Comparison of Predicted Versus Actual At-Risk Student Grades

Non-Intervention

9 am: ID

\begin{tabular}{lll} 
& d & \\
\hline EGi & D & C \\
CHa & D & D \\
DKl & D & C \\
WKo & D & D \\
MLe & D & D \\
WMa & D & F \\
VVa & D & F
\end{tabular}

$$
\begin{aligned}
& \mathrm{GPA}=1.00 \\
& \mathrm{Net}=0
\end{aligned}
$$

1 pm: ID Predicte Actual

\begin{tabular}{lll} 
& d & \\
\hline RBa & D & D \\
JCr & D & F \\
BGo & D & D \\
RHu & D & B \\
PKi & D & B
\end{tabular}

\begin{tabular}{|c|c|c|c|}
\hline $\begin{array}{l}10 \\
\text { am: }\end{array}$ & ID & $\begin{array}{c}\text { Predicte } \\
\text { d }\end{array}$ & Actual \\
\hline & $\mathrm{DBa}$ & $\mathrm{F}$ & $\mathrm{F}$ \\
\hline & $\mathrm{DBa}$ & $\mathrm{D}$ & $\mathrm{C}$ \\
\hline & $\mathrm{FGa}$ & $\mathrm{D}$ & $\mathrm{F}$ \\
\hline & PGe & $\mathrm{D}$ & $\mathrm{C}$ \\
\hline & DKa & $\mathrm{F}$ & $\mathrm{F}$ \\
\hline & $\mathrm{JKe}$ & $\mathrm{D}$ & $\mathrm{D}$ \\
\hline & JLa & $\mathrm{D}$ & B \\
\hline & $\mathrm{POb}$ & $\mathrm{D}$ & $\mathrm{F}$ \\
\hline & KTi & $\mathrm{D}$ & $\mathrm{C}$ \\
\hline & & \multicolumn{2}{|c|}{$\mathrm{GPA}=1.11$} \\
\hline
\end{tabular}

Intervention

2 pm: ID Predicte Actual

\begin{tabular}{lll} 
& d & \\
\hline KHa & D & D \\
EJo & D & D \\
RMi & D & F \\
CMo & D & D \\
ESt & D & C
\end{tabular}




\begin{tabular}{|llllll|}
\hline TMa & D & D & KSt & D & B \\
JPo & D & F & JVa & F & C \\
& & AWi & D & C \\
& & MWo & D & D \\
& GPA $=1.29$ & & GPA $=1.44$ \\
& Net $=+2$ & & \\
\end{tabular}

Table 2. Comparison of Predicted and Actual Grades for At-Risk and Non-At-Risk Students
10:00 am
2:00 pm

Exper. Non-Exper. Exper. Non-Exper.

$\begin{array}{lllll}\text { Pred. } & 1.581 & 3.429 & 1.500 & 3.057\end{array}$

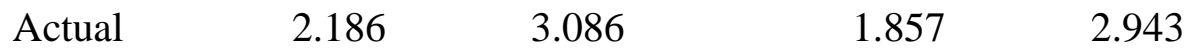

$\begin{array}{lllll}\text { Difference } & 0.605 & -0.343 & 0.357 & -0.114\end{array}$

Average for intervention: +0.481

Average for non-intervention: -0.2285 
Our study has simply reinforced the pedagogical need to give active and directed attention to students who tend to ìget lost in the systemî and ìfall into the cracks.î Hopefully, instructors of large engineering economy classes at other universities will use various intervention methods to attempt to rescue students who are likely to perform poorly. Probably the most easily obtained predictor of a studentís being at-risk is his/her GPA. Why not make an extra effort to encourage students with low GPAís to get ìplugged intoî your class rather than writing them off as disinterested? You may discover that these students are highly capable but are not properly motivated to reach a higher standard than their GPA would suggest. At Virginia Tech we will continue to search for better ways to help potential engineering graduates who may have gotten off to a rocky start in their academic studies.

\section{References}

1. DeGarmo, E. P., W. G. Sullivan, J. A. Bontadelli and E. M. Wicks, Engineering Economy (Tenth Edition), Prentice Hall, Upper Saddle River, NJ, 1997.

2. Sullivan, W. G. and S. F. Daghestani, ìMultivariate Analysis of Student Performance in Large Engineering Economy Classes,î ASEE Annual Conference Proceedings, Milwaukee, WI, June 16, 1997, Session 1239.

\section{Biographies}

WILLIAM G. SULLIVAN is Professor of Industrial and Systems Engineering at Virginia Polytechnic Institute and State University. He is the author/co-editor of eleven books and over 120 technical papers. One of Dr. Sullivan's books, Engineering Economy (Macmillan), is now in its tenth edition. Dr. Sullivan's current research interests include justification of advanced manufacturing technologies and activity-based costing applied to the design process.

DAVID G. MARTIN received a Bachelorís Degree in Industrial Engineering in 1989 and a Masterís Degree in Industrial Engineering in 1992. Both degrees were conferred by West Virginia University, Morgantown, West Virginia. He is currently working towards his Doctorate in Industrial and Systems Engineering at Virginia Tech. 